\title{
A PERSPECTIVA DOS ESTUDANTES DIANTE DA VIOLÊNCIA QUE ENFRAQUECE AS RELAÇÕES INTERSUBJETIVAS NO COTIDIANO ESCOLAR
}

\author{
ESTEVES, Pâmela Suélli da Motta (Brasil, Rio de Janeiro, Rio de Janeiro) ${ }^{1 *}$ \\ 1 Universidade do Estado do Rio de Janeiro \\ ORCID ID: https://orcid.org/0000-0002-9555-2099
}

\begin{abstract}
RESUMO
Bullying é um tipo específico de violência escolar caracterizado por atitudes agressivas de todas as formas, praticadas intencional e repetidamente, que ocorre devido à dificuldade dos estudantes em conviver/aceitar suas próprias diferenças culturais e identitárias que são construídas e reconstruídas no ambiente escolar. Mesmo compreendendo o bullying como um tipo específico de violência escolar, a questão da motivação para sua ocorrência continua sem explicações racionáveis, por isso este texto defende que o não reconhecimento da diferença constitui a principal motivação para o comportamento bullying. A partir dessa ponderação, o texto busca compreender o significado que os estudantes atribuem ao bullying na construção do cotidiano escolar. Para tanto, buscou-se ouvir os estudantes acerca das práticas de bullying, procurando entender como essa violência afeta suas formas de socialização e interfere na construção de suas subjetividades. Do ponto de vista metodológico, o texto analisa relatos de entrevistas realizadas com estudantes de ensino médio de uma escola estadual de grande porte localizada no Rio de Janeiro. A partir dos relatos, três perspectivas teóricas são elencadas com o intuito de compreender a percepção sobre o bullying: (1) as contribuições pioneiras de Dan Olweus (2007); (2) a filosofia do reconhecimento de Charles Taylor; (3) e os argumentos de Hannah Arendt (1999) acerca do processo de banalização da maldade. O entrelaçamento das narrativas dos estudantes com os conceitos do referencial teórico utilizado apontou alguns achados: os estudantes compreendem o bullying como uma violência escolar, mas, devido à banalização do termo e à marginalização do problema, a maioria dos discentes não consegue dimensionar a gravidade e os efeitos dessa prática. Os conflitos que possuem maior propensão a se transformar em bullying são aqueles marcados pela diferença, geralmente atitudes preconceituosas e discriminatórias. Para além da dificuldade em reconhecer as diferenças, o bullying é também oriundo de um processo de naturalização e banalização da maldade.
\end{abstract}

\section{PALAVRAS-CHAVE}

Bullying. Estudantes. Diferença e banalidade do mal.

\section{THE STUDENTS' PERSPECTIVE ON THE VIOLENCE THAT WEAKENS THE INTERSUBJECTIVE RELATIONS IN THE DAILY SCHOOL}

\begin{abstract}
Bullying is a specific type of school violence characterized by aggressive attitudes in all forms, practiced intentionally and repeatedly, due to students' difficulty in cohabiting / accepting their own cultural and identity differences that are built and rebuilt in the school environment. Even though we understand bullying as a specific type of school violence, the issue of motivation for bullying
\end{abstract}

Educação \& Formação, Fortaleza, v. 4, n. 11, p. 60-81, maio/ago. 2019

DOI: https://doi.org/10.25053/redufor.v4i11.227

http://seer.uece.br/redufor 
continues without rationalizing explanations, so this paper argues that failure to recognize difference is the main motivation for bullying behavior. From this consideration, the text seeks to understand the meaning that students attribute to bullying in the construction of daily school life. In order to do so, we seek to listen to students' narratives about bullying practices, trying to understand how this violence affects their forms of socialization and interferes in the construction of their subjectivities. From the methodological point of view, the text analyzes reports of interviews with high school students of a large state school located in Rio de Janeiro. From the reports, three theoretical perspectives are listed in order to understand the perception about bullying: (1) the pioneering contributions of Dan Olweus (2007); (2) Charles Taylor's (2009) philosophy of recognition; (3) and Hannah Arendt's (1999) arguments about the process of trivializing evil. The interweaving of students' narratives with the concepts of the theoretical reference used pointed us to some findings: students understand bullying as a school violence. But because of the banalization of the term and the marginalization of the problem, most students can not size the severity and effects of bullying. The conflicts that are more likely to turn into bullying are those marked by difference, usually biased and discriminatory attitudes. In addition to the difficulty in recognizing the differences, bullying also comes from a process of naturalization and trivialization of evil.

\title{
KEYWORDS
}

Bullying. Students. Difference and banality of evil.

\section{LA PERSPECTIVA DE LOS ESTUDIANTES ANTE LA VIOLENCIA QUE DEBILITA LAS RELACIONES INTERSUBJETIVAS EN EL COTIDIANO ESCOLAR}

\section{RESUMEN}

El bullying es un tipo específico de violencia escolar caracterizado por actitudes agresivas de todas las formas, practicadas intencional y repetidamente, que ocurre debido a la dificultad de los estudiantes en convivir / aceptar sus propias diferencias culturales e identitarias que son construidas y reconstruidas en el ambiente escolar. En la mayoría de los casos, la cuestión de la motivación para su ocurrencia continúa sin explicaciones racionables, por lo que este texto sostiene que el no reconocimiento de la diferencia constituye la principal motivación para el comportamiento bullying. A partir de esa ponderación, el texto busca comprender el significado que los estudiantes atribuyen al bullying en la construcción del cotidiano escolar. Para ello, se buscó oír a los estudiantes acerca de las prácticas de bullying, buscando entender cómo esa violencia afecta sus formas de socialización e interfiere en la construcción de sus subjetividades. Desde el punto de vista metodológico, el texto analiza relatos de entrevistas realizadas con estudiantes de enseñanza media de una escuela estatal de gran porte ubicada en Río de Janeiro. A partir de los informes, tres perspectivas teóricas se enumeran a fin de comprender la percepción de la intimidación: (1) las contribuciones pioneras de Dan Olweus (2007); (2) la filosofía del reconocimiento de Charles Taylor; (3) y los argumentos de Hannah Arendt (1999) sobre el proceso de banalización de la maldad. El entrelazamiento de las narrativas de los estudiantes con los conceptos del referencial teórico
\end{abstract}

Educação \& Formação, Fortaleza, v. 4, n. 11, p. 60-81, maio/ago. 2019

DOI: https://doi.org/10.25053/redufor.v4i11.227

http://seer.uece.br/redufor 
utilizado apuntó algunos hallazgos: los estudiantes comprenden el bullying como una violencia escolar, pero, debido a la banalización del término y a la marginación del problema, la mayoría de los discentes no consigue escalar la gravedad y los efectos de esa práctica. Los conflictos que poseen mayor propensión a convertirse en bullying son aquellos marcados por la diferencia, generalmente actitudes prejuiciosas y discriminatorias. Además de la dificultad en reconocer las diferencias, el bullying es también oriundo de un proceso de naturalización y banalización de la maldad.

\section{PALABRAS CLAVE}

Bullying. Estudiantes. Diferencia y banalidad del mal.

\section{INTRODUÇÃO}

Este texto tem o objetivo de compreender o significado que os estudantes atribuem ao bullying na construção do cotidiano escolar. Para tanto, buscamos ouvir as narrativas dos discentes acerca das práticas de bullying, procurando entender como essa violência afeta suas formas de socialização e interfere na construção de suas subjetividades. Nesse sentido, este texto traz a percepção dos estudantes do Colégio Guanari, uma escola pública estadual de grande porte situada no Rio de Janeiro. As narrativas são oriundas de uma pesquisa qualitativa que combinou a aplicação prévia de um questionário objetivo com a elaboração de um roteiro de entrevistas semiestruturado. As informações coletadas e analisadas a partir dos dados dos questionários foram agrupadas em categorias analíticas e transformadas em questões que compuseram 0 roteiro de entrevistas.

Para facilitar o entendimento do leitor, dividimos este artigo em duas partes. $\mathrm{Na}$ primeira parte, apresentamos de modo sucinto o bullying como uma violência escolar específica e sinalizamos a conceituação que foi utilizada na execução da pesquisa. Ainda nesse momento, trazemos uma descrição do campo onde a pesquisa foi realizada, concentrando informações importantes para a compreensão das narrativas dos educandos. Na segunda parte, traçamos um perfil dos respondentes e estruturamos a análise das respostas a partir de trechos advindos das próprias narrativas dos estudantes. A todo momento de investigação das entrevistas, buscamos relacionar 0 entendimento que os discentes possuem sobre o bullying com o referencial teórico consultado: Charles Taylor (2009), Dan Olweus (2007) e Hannah Arendt (1999), que fundamentaram a pesquisa. 
A pesquisa foi realizada no Colégio Guarani, que é considerado uma escola de excelência da rede estadual de ensino. A escola está localizada na Zona Sul do Rio de Janeiro e atende majoritariamente a alunos oriundos das comunidades da Rocinha e do Vidigal. Do ponto de vista metodológico, buscamos compreender as narrativas dos estudantes através de uma abordagem quantitativa/qualitativa que teve início com a aplicação de um questionário identificado apenas pelo número de matrícula (amostra aleatória) para 147 discentes do ensino médio. A análise dos dados do questionário foi utilizada para a elaboração do roteiro de entrevistas semiestruturadas. As entrevistas foram direcionadas a 10 alunos respondentes do questionário. Os educandos foram selecionados a partir de suas disponibilidades e desejo de fazer parte das entrevistas. Todos os estudantes residem nas comunidades do entorno, seis meninos e quatro meninas entre 14 e 16 anos compuseram a amostra. O roteiro das entrevistas foi composto por três blocos de questões: (1) relacionamento entre pares; (2) percepção sobre o bullying; (3) possíveis causas e consequências do bullying.

O termo "bullying" é um anglicanismo, uma palavra de etimologia inglesa utilizada em quase todo o mundo ocidental para explicar casos específicos de violência escolar. O alto índice de casos de violência escolar e a gravidade de alguns casos que chegaram a resultar em suicídios levaram pesquisadores ingleses e noruegueses a definirem um termo para expressar alguns comportamentos agressivos que acontecem nas escolas. O bullying começou a ser estudado na década de 1970 na Suécia. A partir de 1990, na Noruega, o professor Dan Olweus, pesquisador da Universidade de Bergen, começou a investigar o assunto a partir de casos de suicídios ocorridos entre adolescentes que sofriam agressões na escola.

Olweus (1978) elaborou as primeiras características para se detectar os casos de bullying e os diferenciou de interpretações errôneas, como gozações isoladas, incidentes, brincadeiras agressivas próprias do processo de amadurecimento de crianças e adolescentes. Olweus (1978) definiu cinco características específicas do bullying: (1) agressões num período prolongado de tempo; (2) desequilíbrio de poder entre 0 
agressor e a vítima; (3) dificuldade da vítima em se defender; (4) ausência aparente de motivos que justifiquem os ataques; (5) atos de violência ocorridos entre pares.

Partindo de Olweus (1978) e da literatura especializada em violência, este texto compreende o bullying como um tipo específico de violência escolar entre pares, caracterizado por comportamentos violentos que envolvem atitudes hostis. Essas atitudes podem violar a integridade física e psicológica dos estudantes, mediante práticas agressivas, intencionais, repetitivas e assimétricas. As motivações para o bullying não são plenamente racionáveis do ponto de vista das justificativas morais e, em geral, exprimem sentimentos de intolerância à diferença.

Iniciamos as entrevistas resgatando os estudos de Olweus (1978) sobre a importância da escola na construção da identidade dos estudantes. Nosso objetivo foi entender como os entrevistados compreendem suas relações intersubjetivas no cotidiano escolar e se temas como conflitos, preconceitos e discriminações apareceriam de maneira mais livre, numa conversa inicial. Acreditamos que a percepção que os estudantes possuem sobre a escola, os professores e os seus pares possa nos ajudar a entender o comportamento desses jovens e ainda compreender melhor as possíveis situações de agressão.

O que mais nos impressionou foi a maneira aberta com que os discentes falaram sobre todos os assuntos, sem rodeios ou indiretas. As entrevistas se transformaram em conversas e em alguns momentos foi difícil mudar de tópico. Percebemos que os estudantes queriam falar, precisavam falar e tinham o que dizer sobre a violência na escola. Não são ingênuos nem desinformados sobre a situação de violência ou mesmo sobre a situação da escola como um todo. Conhecem as regras da escola, discordam e, segundo suas afirmações, estão cientes e convencidos sobre quando estão certos ou errados. Possuem opiniões contundentes sobre a maneira como a escola lida com o bullying e não têm receio em dizer as consequências negativas que o bullying traz para a vida escolar.

\section{2 "FUI JULGADA QUANDO ENTREI NA ESCOLA"}

Com isso de grupos, obviamente fui julgada quando entrei na escola, quem é do meu grupo não tem problema comigo, nem eu com eles, e quem não é, mas me conhece, sabe que sou uma pessoa legal. Porém, quem me julgou e viu que não

Educação \& Formação, Fortaleza, v. 4, n. 11, p. 60-81, maio/ago. 2019

DOI: https://doi.org/10.25053/redufor.v4i11.227

http://seer.uece.br/redufor 
tenho os pré-requisitos para ser uma 'famosinha' sempre encontra problemas comigo, ou tenta me subjugar, mas não tenho problemas com eles, a não ser que eles arranjem comigo, apesar de que tento ser sempre amigável com todos, mesmo com aqueles que não gostam de mim. (E2).

Perguntamos aos estudantes como eles se relacionam com seus colegas, com os professores e com a direção. O que mais nos surpreendeu foi que todos os estudantes afirmaram ter um bom relacionamento com os professores e destacaram 0 distanciamento da direção e da coordenação. Já em relação ao relacionamento entre pares, as respostas foram diversas, mas, em geral, os alunos destacaram que se relacionam bem.

A relação que eu possuo com os meus colegas é harmônica, mesmo apresentando diferenças. Quase não me dirijo aos professores, mas, quando falo com eles, há uma satisfação muito grande, pois eles ouvem com muita atenção e tentam ajudar de alguma forma. (E5).

Ruim. Eu estou repetindo o $1^{\circ}$ ano e, desde o ano passado, eu tinha um amigo, que repetiu e saiu da escola. Eu só tinha esse amigo e agora tenho duas amigas, que são de outras turmas. Na minha sala, esse ano é um pouco ruim também, porque converso com poucos alunos, mas, sei lá, eu também sempre fui diferente. Eu sempre fiquei a maioria das vezes sozinho, no meu canto, desenhando. [...] Com a direção, tanto faz, não faz diferença para mim. Eu quase não falo com a direção. Com os professores é o contrário, eu sempre tive um bom relacionamento com os professores, até mais com os professores do que com o pessoal da minha sala. (E1).

Hum, eu sou meio antipática com isso, porque hoje as pessoas estão muito abusadas, principalmente os jovens, e estão perdendo muito o limite do que fazer e do que não fazer. Mas, no geral, tenho um relacionamento razoável com meus colegas. A direção sempre foi muito afastada de tudo, então não tenho muito contato. E com os professores, com alguns deles, eu tenho muito contato e admiro muito alguns, acho que vou levar como exemplo para a minha vida toda. (E3).

$\mathrm{O}$ relato de $\mathrm{E} 1$ nos chamou a atenção. Ele afirmou não ter um bom relacionamento com os demais estudantes, mas justificou essa situação afirmando sua própria diferença, chegando a dizer que sempre foi diferente e que sempre gostou de ficar mais isolado. Segundo a hipótese construída para esta pesquisa, quando a diferença provoca intolerância, o bullying se instaura. Mas, até aqui, considerávamos o olhar do aprendiz agressor para a vítima. O diferencial no depoimento de E1 é que o olhar parte dele, como alguém que se sente diferente e que compreende que não é aceito por todos devido à sua diferença. Segundo o que pudemos observar, o discente não tem nenhuma diferença física que se sobressaia. Não é muito gordo, nem muito magro, nem baixo, nem muito alto, não tem espinhas ou sinais, não é orelhudo, olhudo, 
bocudo ou nada parecido. Declarou-se heterossexual, não é negro, nerd ou "sem noção". Perguntamos-lhe por que se sentia diferente, ao que ele respondeu: "Acho que sou diferente porque sou mais sensível a algumas coisas. Na minha turma tem três divisões, o grupo das meninas, o grupo dos meninos e eu. Eu não falo com ninguém, não gosto de ninguém. E eles também não gostam de mim" (E1).

A diferença apontada por E1 é uma diferença comportamental. $O$ fato de ser mais tímido e gostar de arte o faz acreditar que seja distinto dos outros meninos devido à sua sensibilidade. Os outros meninos são mais populares, jogam futebol e se comportam de maneira socialmente compreendida como mais masculina. É expressivo o quanto a escola é uma instituição homogeneizadora e padronizadora ao ponto de o estudante se sentir diferente por não se enquadrar no padrão da maioria. Poderíamos afirmar que, pelas interpretações que fizemos até aqui, E1 tem grandes chances de ser ou se tornar uma vítima de bullying, não apenas porque é tímido, sensível e introspectivo, mas porque se sente diferente, e isso, segundo seu próprio relato, atinge-o negativamente.

Ainda com a temática dos relacionamentos entre pares, perguntamos aos estudantes sobre a formação de grupos nas turmas e em que grupos eles se encaixariam. Essa pergunta foi considerada porque os dados dos questionários nos mostraram que a formação de grupos contribui para a ocorrência do bullying. Os dez educandos afirmaram que as turmas são divididas em grupos bem definidos, os quais, na maioria das vezes, se formam por afinidades.

Alguns relatos indicaram que os grupos se formam "normalmente", mas que sobrevivem recrutando alunos novatos de acordo com seus próprios pré-requisitos. "Grupos sempre têm. Têm aqueles que estudam muito, aqueles que colam e aqueles que não fazem nada nunca. Acho que os grupos se formam normalmente" (E6). Essa percepção dos aprendizes permite ainda que consigam identificar e rotular os grupos a partir de suas principais características e desejos, sem questionar tal "normalidade". Assim, conseguem destacar que a turma é bastante fragmentada e que, conforme suas avaliações, isso é ruim. Vale destacar que E3, por exemplo, não sabia ao certo a que grupo pertencia. Assim, parece-lhe ser mais fácil rotular do que se entender dentro dos rótulos, tal como veremos nas afirmações seguintes.

Os relatos nos mostraram que a formação de grupos é um processo considerado normal e que sempre obedece a determinados critérios, pode ser por afinidades, 
comportamentos e/ou aspectos físicos. Porém, alguns estudantes mencionaram que nem todos os jovens são inseridos nos grupos. Há aqueles que não conseguem ou não desejam fazer parte de um grupo e acabam ficando isolados, realizando atividades sempre individualmente. Se a socialização, a interação, é algo importante para a construção das identidades, ainda mais entre crianças e adolescentes, então esses discentes isolados (excluídos ou autoisolados) nos preocupam, pois, muitas vezes, o grupo funciona como um espaço que protege seus integrantes, produzindo sentimento de pertença.

Elias e Scotson (2000) identificaram esse movimento de pertencimento e exclusão em Os estabelecidos e os outsiders. O livro é um relato etnográfico que descreve a relação de poder entre dois grupos de moradores que não se diferenciavam quanto a seu tipo de ocupação, educação, nacionalidade, classe social, mas sim no que se referia ao tempo em que residiam na comunidade. O grupo dos estabelecidos estigmatizava os moradores mais novos, tratava-os como pessoas de valor inferior, rotulando-os como forasteiros, "os de fora". Entre os outsiders não havia coesão. Pelo pouco tempo juntos, ainda não haviam conseguido construir laços de uma comunidade efetiva. Guardadas as suas devidas proporções, consoante os relatos levantados, esse processo parece nos permitir entender alguns acontecimentos do Colégio Guarani.

Os grupos se formam, constituem identidades próprias e funcionam com um guarda-chuva de proteção para os seus integrantes. Mesmo aqueles grupos menores e mais fracos, do ponto de vista do poder estabelecido dentro das turmas, conseguem se proteger, pois compartilham determinadas características e afinidades e lutam para que essas sejam mantidas como uma marca grupal. Não estamos considerando que os adolescentes vão instituir uma semântica coletiva no sentido honnethiano ${ }^{1}$ ou que seus pequenos grupos escolares vão produzir movimentos sociais identitários, mas estar fora de um grupo pode significar estar desprotegido.

Entre grupos, o bullying também acontece, mas tanto para os agressores quanto para as vítimas saber que aquela situação é compartilhada por outros conforta e, de certa maneira, dilui o sentimento de inferioridade. E1, por exemplo, nunca conseguiu fazer parte de um grupo e acreditamos que isso possa ter contribuído para que se tornasse uma vítima de bullying, como veremos adiante. Tendo em vista que E1 era

1 Termo faz referência aos estudos do filósofo alemão Axel Honneth sobre a necessidade de reconhecimento social nas sociedades atuais.

Educação \& Formação, Fortaleza, v. 4, n. 11, p. 60-81, maio/ago. 2019

DOI: https://doi.org/10.25053/redufor.v4i11.227

http://seer.uece.br/redufor 
repetente, poderíamos supor que, sem a proteção de um grupo, seria provável fracassar academicamente na escola? Sem a identificação com um grupo, a escola se tornaria uma experiência sem sentido? Com os nossos dados, não podemos nem pretendemos responder a essas questões, mas elas ficam aqui para que nos façam pensar sobre elas.

Entretanto, a formação de grupos nem sempre resulta na proteção dos estudantes que se sentem outsiders. Os grupos dos estabelecidos, na maioria das vezes, é composto pelos autores do bullying. $\mathrm{Na}$ fala de E3, eles são identificados como "famosinhos", na de E9, como os "populares". São estudantes que se sentem poderosos e buscam a manutenção desse poder irradiando medo e insegurança naqueles que são desprotegidos, fora de qualquer relação que os deixem confortáveis dentro da instituição escolar. Há também um terceiro caso, que são aqueles grupos fragmentados, formados por discentes que competem entre si. Nesse caso, o grupo pode não funcionar como um mecanismo de proteção contra o bullying, pelo contrário, os educandos que por algum motivo se submeterem a tudo que for dito podem se tornar vítimas de bullying dentro do próprio grupo.

Os grupos se formam a partir de estereótipos e, algumas vezes, por afinidade. Minha sala de aula é extremamente fragmentada. Há a presença de três grupos: 0 grupo dos 'populares', que é formado pelas pessoas super descoladas; o outro grupo é o das pessoas que curtem games e gibis; e o terceiro grupo é formado por meninas que se identificam umas com as outras, mas que são extremamente competitivas entre si. Posso até dizer que é insuportável. Bem, acho que 'pertenço' ao grupo das meninas competitivas entre si. Nesse grupo, umas se identificam, outras não mas nesse grupo tem uma 'chefe'; tem também uma que muda de opinião conforme a pessoa e nunca aceita estar errada; outra que só pensa em seu próprio benefício e algumas são bem legais, extrovertidas e sinceras. (E9).

A competição entre grupos é também um elemento encontrado nas pesquisas de Gomes (2004) e Rossato S. e Rossato G. (2013). É interessante que os grupos fragmentados são compostos por subgrupos que obedecem a lideranças específicas. Em geral, esses subgrupos compartilham determinados aspectos que os transformam em um grupo, ainda que fragmentado. O relato da E9 expressa exatamente esse relacionamento sobrecarregado dentro de um grupo fragmentado em vários subgrupos. Os grupos que apresentam essas características tendem a ser mais fortes do que os outros, pois, apesar das diferenças internas, há os elementos de aglutinação, no caso relatado, é a competição entre as meninas. Tal comportamento funciona como um elemento de fortalecimento que dificulta que o grupo seja desrespeitado por outros grupos, ainda que provoque muita

Educação \& Formação, Fortaleza, v. 4, n. 11, p. 60-81, maio/ago. 2019 
tensão dentro do próprio grupo: "[...] posso dizer que é insuportável" (E9). Contudo, isso não livra esses grupos fragmentados do bullying, mas contribui para um bullying diferenciado, que se apresenta entre os subgrupos ou no interior dos subgrupos.

\title{
3 "QUEM NÃO SE ENQUADRA É PRESA FÁCIL PARA O BULLYING"
}

O bullying é uma violência, atitudes feitas por idiotas que machucam a pessoa. Quem não se enquadra é presa fácil para o bullying. E uma discriminação, uma forma de humilhar quem não sabe se defender. (E5).

Após compreender a percepção que os estudantes possuíam sobre a escola, como se relacionavam entre si e o que pensavam sobre os grupos que se formam dentro do espaço escolar, buscamos investigar o que eles pensavam sobre o bullying.

\begin{abstract}
É quando você chacota uma pessoa, tipo: o bullying é a zoeira não autorizada. Para mim, a diferença entre o bullying e a zoeira é que a zoeira é recíproca, você brinca com seus amigos e eles brincam de volta com você. O bullying não, você faz só com quem não sabe se defender. Acho que pode ter agressões verbais e físicas e vai piorando conforme o tempo. (E1).

O bullying é sempre um julgamento preconceituoso. [...] Esses pré-requisitos, quando são diferentes do seu, você julga, é quase que automático. Mas, quando você continua julgando, achando que ser diferente de você é errado, para mim o bullying começa aí. E, muitas vezes, do bullying se desenvolve algo muito mais sério, como a homofobia. (E10).
\end{abstract}

Os dois relatos chamam a atenção para pontos de vista diferentes. E1 definiu o bullying como uma zoeira não autorizada. Ou seja, ele atribui à vítima o direito de decidir se é bullying ou não. Quando o estudante aceita a zoeira e a contrapõe da mesma forma, é uma brincadeira, mas, quando o estudante não consegue revidar e se ofende, então, segundo o depoimento, essa situação seria o bullying. Essa é uma maneira muito peculiar de avaliar a situação, pois torna ainda mais imperceptível a fronteira entre o bullying e as brincadeiras escolares. $\mathrm{O}$ aluno ainda advertiu que o bullying acontece com aqueles que não sabem se defender, colocando, mais uma vez, a definição a partir do ponto de vista da vítima, isto é, se a vítima está numa situação de desvantagem, ela não consegue reagir e impor autoridade/respeito. Poderia também ser entendido como responsabilização da vítima, ou seja, o bullying não se tornaria um problema se os afetados por ele soubessem se defender. No entanto, acreditamos que o depoimento, mais do que julgar as vítimas, assume o ponto de vista delas. É interessante que a 
responsabilização da vítima foi destacada explicitamente por outros três educandos. É fato que, sendo uma agressão, o bullying sempre vai ser desautorizado, mas a questão é até onde podemos responsabilizar a vítima por não ter conseguido se impor, responder à altura, reagir com capacidade de desautorizar a ofensa?

O segundo relato desloca, sem dúvidas, o referencial e retira da vítima o ônus do bullying. E10 revelou entender o bullying como um julgamento preconceituoso. Nesse caso, o bullying acontece porque alguns estudantes se acham no direito de julgar pejorativamente o outro. Quando esse julgamento se transforma em ofensas e agressões, temos o bullying instaurado. A discente destacou que esses julgamentos pejorativos acontecem porque alguns alunos entendem que ser diferente é errado e, se é um erro, logo deve ser rechaçado. Essa visão se articula com a nossa hipótese de que, em algumas situações, a diferença pode produzir intolerâncias e se transformar em bullying, o que significa afirmar que o bullying é um tipo de violência escolar motivado pela dificuldade que os educandos possuem em conviver com as diferenças.

Eu sei o que é bullying, mas não sei se saberia reconhecer. Acho que, às vezes, os garotos exageram nas brincadeiras com o próprio grupo. (E6).

Bullying, para mim, é uma coisa que alguém faz para machucar, no sentido de ofender, pode ser verbal ou pode ser agressão física também. (E4).

Bullying é uma forma de brincadeira maldosa, sem limites e sem respeito. (E5).

Três estudantes associaram o bullying às brincadeiras de mau gosto feitas com 0 objetivo de ofender, machucar e agredir. E6 levantou a questão de o bullying acontecer dentro do próprio grupo como ressaltamos anteriormente.

No geral, os estudantes demonstraram ter consciência dos efeitos do bullying e considerá-lo uma prática negativa que prejudica os relacionamentos na escola. $\mathrm{Na}$ intenção de deixar os relatos mais precisos, perguntamos aos aprendizes se existia bullying no Colégio Guarani. Nas respostas positivas, perguntamos como acontecia e pedimos que narrassem alguma situação.

Na minha escola, o bullying é visto quando as pessoas são motivo de piadas, são
excluídas, motivos de risadas. Às vezes, isso é cometido pelos próprios amigos,
como se fosse só 'zoeira', mas, mesmo assim, isso é bullying. [...] Muitas vezes,
o bullying é verbal, mas, quando não é 'exterminado', pode virar físico, o que é
tão pior quanto o verbal. [...] Para mim, o bullying tem total efeito quando a
pessoa que está sofrendo por causa disso se deixa abater e não faz nada contra.
Não conheço ninguém que não tenha feito nada contra, porém conheço alguns
casos que pessoas sofreram com isso, mas fizeram algo contra. Minha prima

Educação \& Formação, Fortaleza, v. 4, n. 11, p. 60-81, maio/ago. 2019

DOI: https://doi.org/10.25053/redufor.v4i11.227

http://seer.uece.br/redufor 
estuda na Escola $X^{2}$ e ela não 'agradou' as pessoas que estudavam com ela, ela foi agredida verbalmente, se sentia constrangida e chegaram a colocar um celular roubado na sua mochila para que ela fosse expulsa da escola. Porém, ela contou para os pais, os pais foram na direção e, se não fosse tomada uma decisão sobre aquilo, eles iriam até a polícia. A direção penalizou os responsáveis, porém minha prima saiu da escola, ela não queria se 'esconder', mas não queria ficar num lugar onde não se sentisse bem. (E9).

O relato da E9 traz alguns fatores importantes que merecem ser destacados. Trata-se de um conflito externo ao Colégio Guarani que ocorreu com uma familiar da estudante. Dada a complexidade da violência narrada, que inclui agressão, constrangimento e roubo, o caso foi resolvido fora da escola. O bullying praticado se transformou em denúncia e o caminho foi a ameaça de judicialização do conflito. Analisando a situação da vítima, podemos pensar que as agressões tiveram consequências graves, pois, apesar de não querer se esconder do conflito, a educanda decidiu abandonar uma escola de prestígio, cujo processo de seleção é um dos mais competitivos do estado. Fica, então, a indagação: como a escola não percebeu que a discente estava sendo perseguida a ponto de ser acusada de ladra? Será que os colegas de turma não testemunharam nada? Por que a aluna não procurou a escola ou a família antes de a situação chegar a esse estágio? Quais tipos de valores são compartilhados pelos estudantes que colocaram o celular na mochila de sua colega para que ela fosse expulsa? Até onde iriam esses aprendizes com o objetivo de fazer o mal à aluna? Não temos essas respostas, mesmo porque esse foi um caso narrado por uma das estudantes entrevistadas e não aconteceu no Guarani, mas não podemos deixar de refletir e tentar compreender situações como essa.

Dos dez estudantes que entrevistamos, oito afirmaram que o bullying fazia parte da realidade do Colégio Guarani. Novamente os discentes ressaltaram a temática da diferença e do bullying serem confundidos com brincadeiras. Também diferenciaram o bullying físico (direto) do verbal (indireto), ressaltando que o segundo é mais frequente. Os alunos narraram casos de bullying com seus colegas e também admitiram que haviam sido vítimas no passado. As narrativas foram todas em tom de reprovação e destacaram o sofrimento que o bullying pode causar.

$\mathrm{O}$ relato de $\mathrm{E} 10$ destacou o mesmo argumento usado por $\mathrm{E} 1$, isto é, o bullying é um tipo de violência não autorizada. Se a vítima reagir e se impor, ela "exterminará" o

2 Refere-se a uma escola pública de prestígio.

Educação \& Formação, Fortaleza, v. 4, n. 11, p. 60-81, maio/ago. 2019

DOI: https://doi.org/10.25053/redufor.v4i11.227

http://seer.uece.br/redufor 
bullying. No caso relatado, a vítima procurou ajuda dos pais e cobrou uma posição punitiva da escola ameaçando denunciar o fato à polícia. A partir das pesquisas de Gomes (2004) e Rossato S. e Rossato G. (2013), sabemos que os estudantes conseguem denunciar as situações vividas para os pais ou para a escola, até porque muitos professores não dão valor à gravidade das práticas de bullying e tendem a rotular como brincadeira de criança.

Quando perguntamos se os alunos conheciam alguém quem já havia praticado bullying, as respostas seguiram o padrão dos questionários. Sete disseram que não conheciam nenhum autor de bullying, mas todos revelaram que conheciam vítimas ou já tinham ouvido falar de casos. Se pararmos para pensar, é contraditório que os discentes conheçam várias vítimas e até consigam narrar os casos com detalhes, mas não saibam quem são os agressores. É possível que tenham ficado com medo de dizer, pois as entrevistas foram gravadas. De qualquer modo, tivemos três relatos que afirmaram conhecer autores de bullying.

Sim, eu já conheci e ainda conheço. Na minha sala, tem um menino que lidera um grupinho do terror. Eles não deixam o Thales ${ }^{3}$ em paz, só porque o coitado é muito mimado pelos pais. Os pais dele são temporão, sabe? Ele não faz nada sozinho. A mãe dele vem buscá-lo. Como pode? Será que ela não vê que ele é zuado. (E4).

Conheço um grupinho de meninas, elas aterrorizam. Elas são bonitas, famosinhas, acham bonito passar na mão de todos os garotos. Elas pegam no pé das virgens, já pegaram no meu pé, mas eu as ameacei de contar para os professores sobre o esquema de cola delas. (E3).

Esse ano não lembro de ninguém, mas ano passado tinha o Diego ${ }^{4}$, que fazia bullying descaradamente com o Edson ${ }^{5}$. Coitado! Mas você não imagina, o Edson se chama Edson Second, sabe por quê? [risos]. O pai dele é Edson Filho, o tio dele é Edson Júnior, o primo dele é Edson Neto. Quando o irmão dele nasceu o pai colocou Edson First e quando ele nasceu virou Edson Second [risos]. Desculpe! Mas não tem como não rir. Ele sofreu muito bullying do Diego. No início a turma ria muito, depois vimos que estava ficando exagerado. (E9).

A partir desses relatos, podemos destacar três pontos que se repetem tanto nos questionários quanto nas entrevistas: (1) o papel da liderança para iniciar as perseguições; (2) o poder dos grupos para proteger ou agredir; (3) a diferença como suposta motivação que os agressores utilizam para eleger as vítimas. Nesse último relato, a questão da diferença é colocada de maneira inusitada. O estudante sofreu

\footnotetext{
3 Nome fictício.

4 Nome fictício.

5 Nome fictício.
}

Educação \& Formação, Fortaleza, v. 4, n. 11, p. 60-81, maio/ago. 2019

DOI: https://doi.org/10.25053/redufor.v4i11.227

http://seer.uece.br/redufor 
bullying por causa da história "engraçada e diferente" que deu origem ao seu nome. Outro depoimento nos ajuda a compreender como a diferença é perseguida na escola.

A escola não é um lugar fácil. Não mesmo! Ser bom aluno e tirar boas notas, isso é o mais fácil. Só que a escola não é só isso, é muito mais. Temos que ter sucesso, ser bonito, popular, falar direito, gostar daquilo que todo mundo gosta, fazer o que todo mundo faz. Se você é um pouquinho diferente, ferrou, vai ser perseguido. (E1).

Praticamente em todas as perguntas os alunos levantaram a intolerância à diferença como o principal motivo para o bullying. Quatro apontaram diferenças significantes entre o bullying sofrido pelas meninas e meninos. Os marcadores de gênero foram destacados como imaginávamos. Em geral, observamos que o bullying sofrido pelas meninas está relacionado à maneira como a mulher é vista pela sociedade. $O$ mesmo ocorre com os meninos quando sofrem ou praticam agressões; nesse último caso, são rotulados como valentões, poderosos e líderes.

Nessa perspectiva, o bullying relacionado às questões de gênero muito se fundamenta no nosso modelo patriarcal e machista de socialização dos meninos e das meninas. $O$ fato de exibir a força perante o grupo é relacionado ao futuro macho, àquele que domina seu território e que resolve seus conflitos utilizando sua força física.

Os meninos estão sempre envolvidos com bullying. Fazem isso para mostrar que são fortes. (E8).

Meninos são mais violentos, perdem a paciência e chamam para a mão. É sempre assim: um grupinho que manda e o restante que obedece. (E2).

Acho que entre os meninos é mais forte, sabe: não levamos desaforo para casa! Não podemos levar. (E7).

Claro que os meninos fazem mais bullying. São uns idiotas, não têm maturidade. É insuportável estudar com eles. (E3).

Esses quatro relatos destacaram a força física dos meninos e o papel social que eles ocupam nas relações entre pares, principalmente nas relações de gênero. Os estudantes assinalaram que, entre os meninos, a força física, o poder e a necessidade de demonstrar domínio são comportamentos sempre presentes. Vale lembrar que, em $A$ dominação masculina, Bourdieu (2002) defende que, como sociedade, estamos inseridos em padrões inconscientes de estruturas históricas da ordem masculina e que, por isso, nossos comportamentos estarão sempre sob o viés dessa ótica. 
Dada a nossa condição patriarcal, a submissão feminina é identificada pela lógica da dominação masculina. Dessa forma, o que é considerado feminino ou masculino foi objetivado do mesmo modo que as características homólogas: alto/baixo; em cima/em baixo; frente/atrás; seco/úmido; claro/escuro, etc.

\begin{abstract}
Esses esquemas de pensamento, de aplicação universal, registram como que diferenças de natureza, inscritas na objetividade, das variações e dos traços distintivos (por exemplo, em matéria corporal) que eles contribuem para fazer existir, ao mesmo tempo em que as 'naturalizam', inscrevendo-as em um sistema de diferenças todas igualmente naturais em aparência; de modo que as previsões que elas engendram são incessantemente confirmadas pelo curso do mundo. (BOURDIEU, 2002, p. 15).
\end{abstract}

De acordo com as interpretações de Bourdieu (2002), identificamos o masculino como forte, dominador, líder, protetor, violento e poderoso. Já o feminino é caracterizado pela passividade, a interioridade e a sensibilidade. Esses aspectos, defendidos pelos anatomistas do século XIX, justificariam a posição social da mulher através de sua anatomia.

Os estudantes que apontaram os meninos como os mais envolvidos nos casos de bullying justificaram utilizando a tríade de características definidoras do patriarcalismo: a força, o domínio e o poder, que funcionam ainda hoje como marcadores de gênero na sociedade brasileira. Mesmo aqueles que demonstraram entender que 0 bullying é mais forte entre as meninas, usaram a mesma chave interpretativa de gênero, ou seja, as mulheres devem competir entre si, subentendendo que elas devem seduzir o macho mais forte.

As meninas foram descritas como vaidosas, fofoqueiras, mimadas, sensíveis. Interessante que essa visão foi compartilhada pelos meninos e pelas próprias meninas. Novamente os marcadores de gênero foram levantados como justificativas, o que significa que, sendo os meninos ou as meninas que mais praticam bullying, a explicação para os dois casos envolve uma discussão dos papéis socialmente esperados de gênero. Tais papéis funcionam como produções de subjetividades (FOUCAULT, 2010).

As meninas sofrem bullying pela questão da aparência, por ser gorda ou magra. Elas valorizam muito a aparência. $E$ com os garotos é mais difícil ser a aparência, porque são mais desleixados, mas é mais porque um não gosta de futebol ou não assiste lutas. As pessoas não sabem lidar com a diferença e o modo de lidar delas é a agressão. (E1).

Educação \& Formação, Fortaleza, v. 4, n. 11, p. 60-81, maio/ago. 2019 
Vamos nos concentrar neste relato. E1 afirmou que o bullying acontece entre os meninos e as meninas e ainda ressaltou que aqueles estudantes que são "estranhos" tendem a se tornar os alvos do bullying, sejam meninos ou meninas. É interessante que a justificativa para o argumento do discente é a diferença, que ele enfatizou em todas as suas falas. Mas, ao mesmo tempo, a diferença foi assinalada como um fator que, de certa forma, igualaria o bullying entre os gêneros, isto é, o aluno apontou algumas características específicas das meninas e dos meninos. Na interpretação dele, as meninas sofrem bullying por se preocuparem com a aparência física, enquanto os meninos não são ofendidos por esse motivo, e sim quando não praticam determinados esportes ou se comportam de determinadas maneiras.

Mesmo considerando que o bullying acontece nos dois gêneros - masculino e feminino -, E1 também resgatou os marcadores de gênero para explicar os motivos do bullying. As meninas se ofendem porque algumas não alcançam o padrão de beleza demarcado, padrão que é construído socialmente e que acompanha a vida das mulheres desde a infância até a vida adulta. São lacinhos, rendas, maquiagens e todo um aparato de enfeites que as transforme em princesas dos contos de fada. Para os meninos, a aparência não é um marcador, pelo contrário, o homem é educado para ser ágil, forte, destemido, ousado e, entre outras características, não valorizar demasiadamente a aparência - "porque isso é coisa de menininha" - e ser um pouco "desleixado", o que se torna, muitas vezes, em um indício da masculinidade. Os meninos são fortes e competitivos, devem jogar futebol, ficar sem camisa, cuspir no chão, mostrar que estão se tornando "homens de verdade". Dessa forma, os educandos foram categóricos em colocar na diferença o principal motivo para o bullying, porém, quando foram interrogados sobre como o bullying se configurava entre os gêneros, percebemos que os marcadores socialmente construídos e definidores da heteronormatividade foram destacados.

Contudo, alguns estudantes afirmaram que o bullying simplesmente acontece. Chegaram a alegar que é um comportamento escolar que não tem diferenças entre meninos e meninas.

Sinceramente não sei. Todos os casos que já vi era um grupo de várias pessoas, meninos e meninas, contra alguém ou um grupo que não 'agradou'. (E6).

Eu nunca conheci ninguém que tenha praticado bullying. Acho que isso de menino e menina não significa nada para quem pratica: pode escolher uma menina ou um menino. (E8).

Educação \& Formação, Fortaleza, v. 4, n. 11, p. 60-81, maio/ago. 2019

DOI: https://doi.org/10.25053/redufor.v4i11.227

http://seer.uece.br/redufor 
Após compreender um pouco mais sobre a percepção que os estudantes tinham do bullying, indagamos o que eles pensavam sobre as consequências do bullying. Perguntamos-lhe, então, se já haviam sofrido bullying; se já haviam testemunhado; como haviam reagido; quem eram e como se comportavam as vítimas e os agressores; que tipo de medidas a escola tomou ou deveria tomar para enfrentar o bullying.

\section{4 "ME PERSEGUIAM, ME AMEAÇAVAM... DEMOROU UM ANO PARA ACABAR"}

Sim. Infelizmente, sim. Demorou um ano para acabar. Elas me perseguiam, me ameaçavam, pegavam o mesmo ônibus que eu só para ficar me encarando. (E8).

Sim, eu já sofri bullying. Eu sou esquisito, foi difícil a turma me aceitar. (E1).

Sim, só que eu era menor. Foi no fundamental. Eu era gordinha. Aí já viu, né? Virei a baleia assassina, Free Wille e muito mais. (E4).

O bullying pode ter vários 'níveis', mas creio que sim, já sofri, mesmo que sendo num grau muito baixo, mas já. (E2).

Não, eu nunca sofri bullying, mas eu sempre tive muito medo, principalmente porque eu sou uma pessoa muito sensível, então, eu não sei, eu tenho medo de alguém me bater ou me humilhar, porque a humilhação com certeza é um tipo de agressão. (E3).

Em primeiro lugar, vale registrar que, nessa questão, quando os estudantes tiveram que responder sobre suas próprias vidas, as falas foram mais curtas. Ninguém narrou detalhadamente as situações ou tentou tornar a resposta mais completa, como vinha acontecendo com os demais exemplos. Cinco alunos afirmaram que já haviam sofrido bullying, mas as respostas foram curtas, diretas e objetivas. Relembrar as agressões pode ser algo doloroso. Nem sempre o resgate da memória é um processo simples, talvez por isso as respostas tenham sido tão sucintas. Apenas dois dos dez entrevistados afirmaram não ter sofrido bullying. Antes de tudo, consideramos que eles estavam seguros dessa afirmação. No entanto, é possível especular que tenham sofrido bullying e não conseguiam admitir, ou que não lembravam mais, ou que não conseguiam identificar. Esse registro é importante, pois, segundo as pesquisas de Olweus (2009) e Rossato S. e Rossato G. (2013), a vergonha é um dado que tem sido recorrente no depoimento das vítimas. Afinal de contas, ser vítima de bullying pode significar fraqueza, medo e covardia. Considerando os achados dessas pesquisas, não podemos 
desconsiderar que os relatos podem estar ausentes ou diminutos devido à vergonha que as vítimas sentiam.

Os estudantes assinalaram a dificuldade em saber se o que aconteceu foi de fato bullying ou uma simples zoeira, principalmente quando estavam entre amigos. Essa fronteira tênue entre o bullying e a brincadeira também foi destacada pelos professores e aparece sempre como uma dificuldade adicional para os educadores e para as famílias no momento de identificar, compreender e solucionar os casos de bullying.

E3 afirmou nunca ter sofrido bullying, mas destacou que esse assunto sempre a perturbou bastante devido ao medo constante de se tornar uma vítima de agressões físicas ou verbais. É interessante ressaltar que, se o bullying provoca esse sentimento de medo, é porque realmente faz parte do cotidiano escolar dos estudantes e afeta diretamente suas vidas. Segundo Rossato S. e Rossato G. (2013), alguns discentes entrevistados responderam que na escola, muitas vezes, é preciso assumir uma identidade falsa para não ser alvo de piadinhas e brincadeiras de mau gosto.

Taylor (2009), quando estudou o processo de construção da identidade moderna, chamou a atenção para ética da autenticidade, a ideia de ser fiel a mim mesmo e exigir a valorização social da própria maneira de ser. Na escola, o bullying pode se transformar em um impedimento para a ética da autenticidade, na medida em que sujeita crianças, adolescentes e jovens a assumirem uma postura que não é verdadeiramente a sua só para serem aceitos. Esse processo pode resultar no reconhecimento errôneo da identidade ou na construção de uma falsa maneira de ser (TAYLOR, 2009).

Para a nossa surpresa, todos os alunos afirmaram que haviam testemunhado $e$ ainda testemunham casos de bullying. Sobre como reagiram nessas situações, as respostas nos ajudaram a compreender um pouco mais nossa hipótese sobre o bullying e a banalidade da maldade. "Sim, já! Não era num grau muito alto, porém sempre pedia para quem estava fazendo parar, porque eles não sabem o que a pessoa que estava passando por isso podia estar sentindo, e isso é errado, seria mais que minha obrigação impedir algo como isso" (E3).

Nesse relato, percebemos que E3 interferiu nos casos de bullying que haviam testemunhado. Pontuou que essa era sua obrigação, isto é, não permitir que seus colegas fossem/sejam agredidos. Nesse caso, segundo nosso entendimento, o mal empregado não foi banalizado. E3 não permitiu que as situações testemunhadas por ela 
fossem adiante. Ela assumiu a responsabilidade e buscou impedir que a agressão se prolongasse. No entanto, em nossas dez entrevistas, esse depoimento foi uma exceção, visto que os demais educandos não haviam reagido demonstrando esse sentimento de indignação e justiça. Pelo contrário, alguns alegaram que não sabiam identificar se a pessoa estava sendo agredida em seus sentimentos e outros responderam que não deveriam se meter, pois na escola cada um cuida dos seus próprios problemas.

Eu não sei ao certo se já testemunhei, porque é muito difícil saber se a pessoa não está levando na esportiva. Como eu disse, eu posso falar que eu já sofri, mas eu sei o que senti. Não tenho como saber o que os outros sentiram, por isso acho que não devo fazer nada. (E1).

Já vi muitos casos, vejo sempre, não acaba assim. Não faço nada. Acho que não é problema meu. (E10).

Testemunho sempre. Não entendo. Acontece mais por causa de apelido, zoação. Mas é estranho, porque eu tenho apelido, me chamam de Sky, minha cabeça é bem grande, né? Você pode ver que tenho um cabeção, mas nunca fiquei triste por isso. E é forte, às vezes, nem atendo pelo meu nome. Até meus primos me chamam de Sky. Não faço nada. O bullying é normal, é da escola, virou algo do dia a dia, acho que não tenho nada com isso. (E7).

Posso dizer que nunca reagi, essa não é minha função. E tem muito palhaço aqui, gente que merece sofrer bullying. (E2).

Sinceramente, eu acho engraçado, sei que pode magoar alguém, mas alguns bullyings são muito divertidos, não tem como não rir. (E6).

Os três primeiros discentes dos depoimentos acima indicaram que haviam testemunhado a prática de bullying, mas que não haviam feito nada. As razões para o consentimento da agressão são múltiplas. E1 disse acreditar que não deve interferir porque não sabe ao certo quando é bullying e quando não é, mesmo já tendo sido uma vítima. E2 e E10 também argumentaram que haviam testemunhado e não haviam reagido. Nesses casos, a justificativa foi individualista e/ou uma autopreservação. A lógica é, mais ou menos, assim: "Se não foi comigo, não é problema meu, então não devo fazer nada". E7 acentuou que o bullying se tornou corriqueiro, já fazendo parte do cotidiano da escola. Podemos interpretar esse relato como uma naturalização do bullying, algo que não podemos lutar contra porque é natural, comum, simplesmente acontece.

Mas os relatos que consideramos mais desafiadores, do ponto de vista da valorização da dignidade humana, foram os de E2 e E6. Esses dois aprendizes relataram que já haviam testemunhado casos de bullying e não haviam reagido. Mas por que não haviam reagido? Não foi porque tiveram medo ou porque não conseguiram 
identificar. Não reagiram porque essa não seria uma função deles, porque ver o outro ser ofendido é divertido e engraçado e porque alguns estudantes merecem essa agressão. Mesmo sabendo que essas práticas podem magoar alguém, E6 admitiu que vale a pena assistir e não interferir apenas para se divertir com a situação.

Se interpretarmos esses relatos à luz do conceito de banalidade do mal proposto por Arendt (1999), podemos cogitar que a banalização da maldade não está somente no autor das agressões, ou seja, naquele que comete o bullying e que, quando é interrogado sobre suas ações, não consegue argumentar de modo racionável e razoável. A ausência de uma explicação justificada pode ser efeito do processo de banalização e naturalização da maldade que estamos vivenciando. Agredir, humilhar e ofender 0 colega e não conseguir justificar essa postura significa não refletir sobre as consequências das próprias atitudes. Trata-se de um comportamento que não leva em consideração a dignidade do outro, porque esse outro não é visto como alguém digno de respeito. O mal feito contra ele não se transforma em algo desprezível, justamente por ser visto como natural, comum, corriqueiro e até permitido no dia a dia escolar.

Mas o deboche, as risadas e o divertimento são argumentos que potencializam a banalidade do mal, que nos revelam o quanto o bullying é cruel e como os estudantes justificam uma postura de conivência com essa prática. Nesse sentido, a banalidade do mal expressada no bullying é, segundo nossa avaliação, distinta da banalidade do mal de Eichmann, porque, quando enviava os judeus para os campos de concentração, o oficial nazista se defendia argumentando que aquela era sua função e que estava cumprindo ordens. Em nenhum momento ele revelou que os judeus eram palhaços e mereciam aquele castigo ou que essa situação Ihe trazia divertimentos. É claro que não podemos esquecer que Eichmann estava em um julgamento no qual o que estava em risco era a sua condenação. Nossos entrevistados estavam numa situação de confiança com a pesquisadora, numa entrevista informal, na qual thes foram garantidos anonimato, confiabilidade e ausência de julgamentos sobre certo ou errado. Insistimos que queríamos apenas opiniões, percepções e reflexões, e não um testemunho em tribunal. Ainda assim, tais depoimentos me deixaram, como pesquisadora, bastante impressionada.

Entre os dez relatos dos alunos, os argumentos foram: (1) impedir o bullying por ser algo errado, por isso não havia obrigação em reagir; (2) dificuldade em identificar se era realmente bullying para poder agir; (3) o bullying é algo do dia a dia, não tem como ser 
impedido; (4) não tenho nada a ver com isso, não é problema meu; (5) algumas pessoas merecem sofrer bullying; (6) é divertido assistir às situações de bullying. Outros quatro estudantes destacaram mais dois argumentos interessantes: a impotência e o medo.

É chato. O bullying é muito constrangedor. Já vi, mas não fiz nada. Não consegui fazer. (E4).

Eu testemunhei, sim. Foi muito ruim, eu tive muita vergonha. Eu não consegui reagir, não consegui 'confrontar' os agressores, eu tive medo de isso se voltar contra mim. Acho que esse é um ponto muito importante. (E5).

Nesses dois relatos, a impotência e o medo estão muito claros. Diante da violência que o bullying explicita, alguns estudantes sabem que é errado, mas não conseguem reagir. Sentem-se impotentes, incapazes de denunciar, de pedir por ajuda ou até mesmo impedir o prolongamento do sofrimento, próprio ou alheio. Por que o bullying provoca esse sentimento de paralisação que impede as testemunhas de denunciá-lo? Esse é um questionamento parcialmente respondido pela literatura especializada. Olweus (2009) assinalou que o medo impede os discentes que testemunham o bullying de tomar alguma providência, seja qual for. Foi exatamente esse medo que identificamos no relato de E5, quando disse: "[...] eu tive medo de isso se voltar contra mim".

Escutando nossos depoentes, acreditamos que seja fundamental que a escola consiga retomar a confiança dos jovens estudantes para que eles se sintam à vontade para denunciar o bullying. Isso requer que a escola compreenda os fatores que motivam o bullying para só então construir estratégias de combate a essa violência escolar.

\section{PALAVRAS FINAIS}

A pesquisa concluiu que os estudantes compreendem o bullying como uma violência escolar, mas, devido à banalização do termo e à marginalização do problema, a maioria dos discentes não consegue dimensionar a gravidade e os efeitos do bullying. Os conflitos que possuem maior propensão a se transformar em bullying são aqueles marcados pela diferença, geralmente atitudes preconceituosas e discriminatórias. Vale destacar que o contexto em que os casos são mais recorrentes é a sala de aula, momento mais intenso de socialização e onde os alunos são obrigados a se manifestar.

Educação \& Formação, Fortaleza, v. 4, n. 11, p. 60-81, maio/ago. 2019 
De acordo com o que pesquisamos no Colégio Guarani e com a literatura que investiga o bullying, na maioria das escolas públicas brasileiras não há estratégias de enfrentamento ao bullying. Os alunos do Colégio Guarani afirmaram que a instituição nunca teve nenhum tipo de projeto ou atividade de debate sobre o bullying. Quando algum caso é relatado, a escola busca solucionar através do diálogo, mas não direciona o olhar para a compreensão das motivações que produzem as práticas de bullying.

\section{REFERÊNCIAS}

ARENDT, H. Eichmann em Jerusalém: um relato sobre a banalidade do mal. Tradução José Rubens Siqueira. São Paulo: Companhia das Letras, 1999.

BOURDIEU, P. O poder simbólico. Tradução Fernando Tomaz. Rio de Janeiro: Bertrand, 2002.

ELIAS, N.; SCOTSON, J. L. Os estabelecidos e os outsiders: sociologia das relações de poder a partir de uma pequena comunidade. Rio de Janeiro: Jorge Zahar, 2000.

FOUCAULT, M. A hermenêutica do sujeito. São Paulo: Martins Fontes, 2010.

GOMES, L. F. Bullying: a violência que bulina a juventude. Revista Síntese de Direito Penal e Processual Penal, Porto Alegre, v. 11, n. 63, p. 211-212, 2004.

OLWEUS, D. Aggression in the schools: Bullies and whipping boys. Washington, DC: Hemisphere, 1978.

ROSSATO, S. M.; ROSSAO TO, G. Educando para a superação do bullying. São Paulo: Loyola, 2013.

TAYLOR, C. Argumentos filosóficos. Rio de Janeiro: Loyola, 2009.

Pâmela Suélli da Motta Esteves (Brasil, Rio de Janeiro, Rio de Janeiro) - Universidade do Estado do Rio de Janeiro (UERJ)

Doutora em Ciências Humanas e Educação pela Pontifícia Universidade Católica do Rio de Janeiro (PUC-Rio). Professora adjunta do Departamento de Educação da Faculdade de Formação de Professores da UERJ. Professora da educação básica no Colégio de Aplicação da PUC-Rio (Colégio Teresiano).

Lattes: <http://lattes.cnpq.br/4300683473472083>.

E-mail: <pamelasme84@gmail.com>.

Recebido em $1^{\circ}$ de agosto de 2018. Aceito em 13 de março de 2019.

Educação \& Formação, Fortaleza, v. 4, n. 11, p. 60-81, maio/ago. 2019

DOI: https://doi.org/10.25053/redufor.v4i11.227

http://seer.uece.br/redufor 